\title{
Microeconometric Search-Matching Models and Matched Employer-Employee Data
}

\author{
Fabien Postel-Vinay ${ }^{1}$ \\ University of Bristol, \\ PSE, \\ CREST-INSEE
}

\author{
Jean-Marc Robin ${ }^{2}$ \\ Université de Paris I-Pantheon-Sorbonne, \\ University College London, \\ Institute for Fiscal Studies
}

January 2006

\footnotetext{
${ }^{1}$ Fabien.Postel-Vinay@bristol.ac.uk. PSE (Paris-Jourdan Sciences Economiques) is a CNRSEHESS-ENPC-ENS joint research unit.

${ }^{2}$ Jean-Marc.Robin@univ-paris1.fr
} 


\begin{abstract}
The recent advent of matched employer-employee data as part of the labor market scholar's toolbox has allowed a great deal of progress in our understanding of individual labor earnings. A growing number of empirical analyzes of available matched employer-employee data sets now combine with the already voluminous literature on empirical wage equations based on individual or household survey data to draw an ever richer picture of wage dispersion, individual wage dynamics, and the productivity-wage relationship.

In this chapter we tour the empirical wage equations literature along these three lines and make a case that viewing it through the lens of structural job search models can help clarify and unify some of its recurring findings. Among other things, we emphasize and quantify the role of matching frictions in explaining the share of "residual" wage dispersion that is left unexplained by the reduced-form approach. Secondly, we quantitatively assess the importance of labor market competition between employers relative to non-competitive wage formation mechanisms (namely, wage bargaining) as a theoretical underpinning of the wage-productivity relationship. Thirdly, we show how search frictions combined with a theoretically founded wage formation rule based on renegotiation by mutual consent can account for the widely documented dynamic persistence of individual wages. We conclude with a list of questions that are open to further research.
\end{abstract}

JEL codes: J64, J31.

Keywords: Labor market frictions, wage distributions, wage dynamics, job mobility, matched employer-employee data. 


\section{Introduction}

Understanding differences between individual wages - both across individuals (wage inequality) and over time (wage dynamics) - is a fundamental motivation of labor economics as a research field. For a very long time, the competitive wage model, whereby individual wages equal the marginal productivity of individual labor supply, was the first and foremost theoretical reference in the empirical literature, in sharp contrast with a theory deeply concerned with imperfect information issues and interrogations about the nature of labor market equilibrium.

The Mincer equations estimated in the 70's and the 80's revealed large differences in wages across education and experience groups, which could be interpreted as productivity differences. Panel data sets on wages, that started to be widely available to labor economists in the 80's, permitted a thorough analysis of the residuals of Mincer equations. This analysis further showed that a large part of wage dispersion resulted from unobserved heterogeneity in individual ability and complex accumulation of idiosyncratic shocks. At that point, the competitive view of wages reflecting individual productivity was left essentially unchallenged. Even inter-industry wage differentials were successfully interpreted within the competitive framework of the Roy model (e.g. Heckman and Honoré, 1990): it suffices to allow workers to differ in several dimensions of industry-specific abilities instead of one single, general-purpose ability dimension.

The advent of matched-employer employee data at the end of the 90's brought this nice series of empirical successes to an end. The estimation of wage equations with person and firm effects by Abowd, Kramarz and Margolis (1999) revealed systematic wage differentials both across individuals and across employers. Moreover, a significant fraction of wage dispersion still remained unexplained. This new empirical evidence is difficult to rationalize within a perfect information framework. The idea that there is more wage variability than the Walrasian model can explain thus started to gain ground among labor economists, who began to turn their interest toward equilibrium models with imperfect information. 
Yet in retrospect, it is still striking to observe how little influence novel theoretical ideas have had on applied work in labor economics over the recent couple of decades. The last twenty years of microeconomic theory, and labor economics is no exception, is all about information imperfections. At the same time, most applied contributions assume competitive markets. Things went very differently in the literature on Industrial Organization. There, oligopolistic competition and auction models received a lot of attention from applied economists. As an example, one can compare the interest that the paper by Berry, Levinsohn and Pakes (Econometrica, 1995) stirred up in the profession (464 citations in Google Scholar ${ }^{1}$ ), with the relative lack of excitement with which the pioneering work of Eckstein and Wolpin (Econometrica, 1990: 59 citations, Review of Economic Studies, 1995: 26 citations) was received.

In this chapter we review the empirical wage equations literature and make a case that viewing it through the theoretical lens of structural job search models can help clarify and unify some of its recurring findings. While we focus on a particular theoretical paradigm (namely, the theory of job search), our broader and more general hope is that, in the future, more theory will irrigate applied labor microeconomics.

Our main theoretical focus in this chapter will be on the family of sequential auction models, which feature labor markets with two-sided heterogeneity (across workers and across firms). Firms compete for workers' services but competition is limited by searchinformation frictions. Between-firm competition forces employers to grant wage raises to their employees, implying that wages monotonically increase over job spells. However, when more productive firms successfully bid workers away from less productive ones, and such worker movements are sometimes associated with voluntary wage cuts. We shall also discuss two important extensions of the basic equilibrium-search-sequential-auction model. Firstly, between-firm competition is not necessarily the only force driving wage dynamics (or mobility). The analysis of matched employer-employee data indeed reveals that imperfect between-firm competition falls short of fully explaining the extent of rent sharing in the economy. We thus extend the model by incorporating bargaining as an

\footnotetext{
${ }^{1}$ All citation numbers were collected at the time of Econometric Society World Congress in London.
} 
additional wage setting mechanism. Secondly, nor can between-firm competition alone account for the full extent of within-firm wage variations, both upward and downward. We thus next consider match productivity shocks and human capital accumulation. At the end of the day, the sequential auction paradigm proves able to incorporate most empirical features of wage data that those wedded to the purely competitive model consider to be fundamental.

The plan of this chapter is as follows. A first part deal with wage dispersion. The second part deals with wage dynamics. We start by reviewing what we learned on wage dispersion from matched employer-employee data. Then, we explain why equilibrium search models are useful tools to comprehend the different heterogeneity components of wage dispersions. The section on wage dynamics presents on-going research aiming at establishing that equilibrium search models can also account for the dynamic patterns of wages.

\section{What do we learn on wage dispersion from matched employer-employee data (MEE)?}

In the past ten years, following Abowd, Kramarz and Margolis's (1999; AKM thereafter $)^{2}$ initial push, many matched employer-employee datasets have been constructed in Denmark, Italy, Sweden, Austria, etc., to estimate wage equations. Matched employeremployee data are obtained by merging two different data sources. One needs:

- one panel of worker data with individual index $i \in\{1, \ldots, I\}$ and time index $t \in$ $\{1, \ldots, T\}$,

- one panel of firm data with individual index $j \in\{1, \ldots, J\}$ and same time index $t \in\{1, \ldots, T\}$,

- a matching function $j(i, t) \in\{1, \ldots, J\}$ that defines worker $i$ 's employer at time $t$.

Worker data usually are register data (employer payroll reports collected for tax purposes). Very often, there is no other information on employers than their administrative

\footnotetext{
${ }^{2} 336$ citations in Google Scholar.
} 
identity. Yet in some cases the wage register data can be merged with firm accounting data (value added, EBIT, book value, etc.). Matching with other individual social security or health insurance data has also been done in some countries (Denmark, Sweden).

Wage equations for MEE data. The model considered by AKM (and in subsequent work by Abowd, Kramarz and coauthors) is a standard error-component model with firm fixed effects:

$$
\begin{aligned}
w_{i t} & =x_{i t} \beta+\psi_{j(i, t)}+\alpha_{i}+u_{i t} \\
& =x_{i t} \beta+\sum_{j=1}^{J} \psi_{j} d_{i t}^{j}+\alpha_{i}+u_{i t}
\end{aligned}
$$

where $w_{i t}$ is the log individual wage, $x_{i t}$ is a vector of time-varying individual characteristics (experience, tenure), $d_{i t}^{j}=\mathbf{1}\{j(i, t)=j\}$ are indicator variables of worker $i$ working at firm $j$ at date $t, \alpha_{i}$ is a time-invariant worker-specific effect (maybe of the form $\alpha_{i}=z_{i}^{\prime} \gamma+v_{i}$, where $z_{i}$ is a vector of observed individual attributes), $\psi_{j}$ is a firm-specific effect, and $u_{i t}$ is some idiosyncratic residual component.

AKM propose to estimate $\beta$, person effects $\alpha=\left(\alpha_{1}, \ldots, \alpha_{I}\right)$ and firm effects $\psi=$ $\left(\psi_{1}, \ldots, \psi_{J}\right)$ by OLS. An immediate problem with this approach is the huge number of parameters to estimate: $I=O\left(10^{6}\right)$ and $J=O\left(10^{5}\right)$. Because of this problem, AKM's initial Econometrica (1999) paper only reports approximate OLS estimates. Yet in more recent work, these authors show how one can exploit the sparse structure of the least squares matrices to come up with computationally feasible OLS estimates (see Abowd, Creecy and Kramarz, 2002). ${ }^{3}$

Bias. For the OLS estimators of $\beta, \psi$ and $\alpha$ to be unbiased, firm-worker assignment must be strictly exogenous, that is:

$$
\left(d_{i t}^{j}\right)_{\substack{t \in\{1, \ldots, T\} \\ j \in\{1, \ldots, J\}}} \perp\left(u_{i t}\right)_{t \in\{1, \ldots, T\}}, \quad \forall i \in\{1, \ldots, I\} .
$$

\footnotetext{
${ }^{3}$ Sparse matrices should become more common use in applied econometrics as available data sets grow larger. Danilov and Magnus (2005) are currently developing sparse matrix techniques for least squares, apparently more powerful and faster than the currently available MATLAB routines.
} 
This is an acceptable assumption so long as $u_{i t}$ has no impact on workers' job mobility decisions. This implies in particular that workers decide whether or not to change employers based on relative values of firm fixed effects $\psi_{j}$.

Then, if mobility is exogenous conditional on firm and worker permanent characteristics, the OLS estimator of $\beta$ is consistent when $I$ tends to infinity for fixed $T .{ }^{4}$ Lastly, the OLS estimator of $\alpha$ and $\psi$ are consistent when $T$ tends to infinity faster than $I$ and $J$.

Finite sample precision. Estimates of $\beta$ and firm effects $\psi$ are obtained by applying OLS to the within-transformed model (1):

$$
w_{i t}-w_{i \bullet}=\left(x_{i t}-x_{i \bullet}\right) \beta+\sum_{j=1}^{J} \psi_{j}\left(d_{i t}^{j}-d_{i \bullet}^{j}\right)+u_{i t}-u_{i \bullet},
$$

where $z_{i \bullet}=\frac{1}{T} \sum_{t=1}^{T} z_{i t}$ for an arbitrary variable $z_{i t}$. Inspection of this latter model brings about a new issue: if workers don't change employers, then $d_{i t}^{j}=d_{i \bullet}^{j}$ for all $j$ and no firm effect can be estimated. In practice, for typical values of $T$ (less than 10 years), few workers will be matched with more than two or three different employers. With such a small amount of worker mobility, regressors are close to collinear and OLS estimates are thus expected to be very imprecise.

OLS estimates of person effects $\alpha$ are then obtained as:

$$
\widehat{\alpha}_{i}=w_{i \bullet}-x_{i \bullet} \widehat{\beta}-\sum_{j=1}^{J} \widehat{\psi}_{j} d_{i \bullet}^{j}
$$

This equation shows that any statistical error affecting firm effects is transmitted to worker effects with a sign reversal. We thus expect a spurious negative cross-sectional correlation between $\widehat{\alpha}_{i}$ and $\widehat{\psi}_{j(i, t)}$ in every year $t$.

To conclude, in practice, OLS estimates of firm and worker effects in model (1) are likely to be both imprecise and spuriously negatively correlated (across individuals) given the limited time dimension and scant worker mobility that characterize most MEE data sets. Moreover, pointwise estimation of each worker and firm effect is of no intrinsic

\footnotetext{
${ }^{4}$ Note that $J$ is likely to be a proportion of $I$ (firms are not bigger in China than in the US or France). It should thus make little sense to discuss asymptotics in $I$ for fixed $J$.
} 
interest: only the joint cross-sectional distribution of $\widehat{\alpha}_{i}$ and $\widehat{\psi}_{j(i, t)}$ is providing useful parameters to interpret (such as its second-order moments which convey information on wage inequality and firm-worker assortative matching). All this suggests that it would be preferable to develop an estimation protocol treating $\alpha$ and $\psi$ as random components. Nonetheless, AKM's technique of directly estimating fixed effects to then deduce arithmetic moments of their empirical distribution is straightforward and certainly conveys useful-albeit noisy-information.

Some results. Table 1 shows some results for French and US data. The first column displays the standard deviation of the left hand side variable and estimated components of the right hand side of model (1). The remaining seven columns show the corresponding correlation matrix.

Interestingly, no component dominates in the explanation of total log wage variance. For France (resp. the US), experience alone explains $29 \%$ of the log wage variance (resp. $5 \%$ ), person effects alone explain $21 \%$ (resp. 24\%), firm effects alone $18 \%$ (resp. 24\%) and the residuals alone explain 32\% (16\%). French and US numbers are similar. Moreover, the correlation between person and firm effects is -0.22 in France and 0.04 in the US, two small numbers which tend to indicate that there is no sorting of workers by firms.

Whatever the precision of these estimates, it seems relatively clear that no effect dominates the others. After filtering wage distribution from the deterministic effects of individual education, experience and inter-industry differentials, a very significant fraction of wage dispersion remains to be explained. What matched employer-employee data show is that there are systematic differences across workers and across firms that cannot be explained by classical individual or market attributes. What's more, after accounting for worker and firm heterogeneity, there is still a significant share of the wage variance that remains unexplained. This residual component may reflect productivity shocks, measurement error or some genuine wage indeterminacy, as we shall later argue. 
Table 1: Correlations of Components of Real Annual Wage Rates

\begin{tabular}{|c|c|c|c|c|c|c|c|c|}
\hline \multicolumn{9}{|c|}{ France 1976-1996 } \\
\hline & St. D. & $w_{i t}$ & $x_{i t}^{\prime} \beta$ & $\alpha_{i}=$ & $z_{i}^{\prime} \gamma$ & $+v_{i}$ & $\psi_{j(i, t)}$ & $u_{i t}$ \\
\hline Log real annual wage rate $\left(w_{i t}\right)$ & 0.9772 & 1.0000 & & & & & & \\
\hline Experience and experience squared $\left(x_{i t}^{\prime} \beta\right)$ & 0.4087 & 0.5377 & 1.0000 & & & & & \\
\hline Person effect $\left(\alpha_{i}\right)$ & 0.5217 & 0.4569 & 0.0698 & 1.0000 & & & & \\
\hline Schooling $\left(z_{i}^{\prime} \gamma\right)$ & 0.1522 & 0.1510 & -0.0469 & 0.2917 & 1.0000 & & & \\
\hline Unobservable $\left(v_{i}\right)$ & 0.4990 & 0.4316 & 0.0872 & 0.9565 & 0.0000 & 1.0000 & & \\
\hline Firm effect $\left(\psi_{j}\right)$ & 0.4665 & 0.4287 & 0.1670 & -0.2225 & 0.0293 & -0.2415 & 1.0000 & \\
\hline Residual $\left(u_{i t}\right)$ & 0.5545 & 0.5675 & 0.0000 & 0.0000 & 0.0000 & 0.0000 & 0.0000 & 1.0000 \\
\hline \multicolumn{9}{|c|}{ US 1990-1999 } \\
\hline & St. D. & $w_{i t}$ & $x_{i t}^{\prime} \beta$ & $\alpha_{i}=$ & $z_{i}^{\prime} \gamma$ & $+v_{i}$ & $\psi_{j(i, t)}$ & $u_{i t}$ \\
\hline Log real annual wage rate & 0.8941 & 1.0000 & & & & & & \\
\hline Experience & 0.6965 & 0.2305 & 1.0000 & & & & & \\
\hline Person effect & 0.8434 & 0.4871 & -0.6085 & 1.0000 & & & & \\
\hline Schooling & 0.2317 & 0.1733 & -0.1527 & 0.2748 & 1.0000 & & & \\
\hline Unobservable & 0.8110 & 0.4571 & -0.5893 & 0.9615 & 0.0000 & 1.0000 & & \\
\hline Firm effect & 0.3586 & 0.4926 & 0.0635 & 0.0445 & 0.0824 & 0.0228 & 1.0000 & \\
\hline Residual & 0.3614 & 0.4042 & 0.0000 & 0.0000 & 0.0000 & 0.0000 & 0.0000 & 1.0000 \\
\hline
\end{tabular}

Source: Abowd, Kramarz, Lengermann, Roux (2003). 
Table 2: Correlations of log wage with heterogeneity components accounting controlling for firm value added

\begin{tabular}{lcccccc}
\hline \hline & St.D. & $w_{i t}$ & $x_{i t} \beta$ & $\alpha_{i}$ & $\gamma \bar{y}_{j(i, t)}$ & $u_{i t}$ \\
\hline Log real annual labor cost $\left(w_{i t}\right)$ & 0.477 & 1.000 & & & & \\
Experience $\left(x_{i t} \beta\right)$ & 0.077 & 0.139 & 1.000 & & & \\
Person effect $\left(\alpha_{i}\right)$ & 0.420 & 0.888 & -0.029 & 1.000 & & \\
Firm effect $\left(\gamma \bar{y}_{j(i, t)}\right)$ & 0.022 & 0.290 & 0.047 & 0.269 & 1.000 & \\
Residual $\left(u_{i t}\right)$ & 0.204 & 0.428 & 0.000 & 0.000 & 0.000 & 1.000 \\
\hline \hline
\end{tabular}

Sample: French DADS data matched with BRN, 1990-2000, including all private sector employees aged 20-50 in initial year.

Using firm accounting data. The preceding statistical analysis made no use of firm accounting data, which (in France) can be matched with the wage register data. We now want to evaluate the extent to which firm effects reflect differences in labor productivity. To answer this question, we regress log wages $w_{i t}$ on employer's mean log productivity (measured by mean log value-added per worker):

$$
w_{i t}=x_{i t} \beta+\alpha_{i}+\gamma \bar{y}_{j(i, t)}+u_{i t}, \quad \text { where } \bar{y}_{j}=\frac{1}{T} \sum_{t=1}^{T} \ln y_{j t} .
$$

We want to think of $\bar{y}_{j}$ as $\psi_{j}+\eta_{j t}$. The more noisy $\bar{y}_{j}$ is as a measure of $\psi_{j}$, the less explanatory power it will have.

Table 2 shows the results of our own estimation. Experience and experience squared, alone, explain $2 \%$ of the log wage variance. Worker effect explain $79 \%$, firm average labor productivity $8 \%$ and the residual $18 \%$. The estimated correlation between firm $\left(\gamma \bar{y}_{j(i, t)}\right)$ and worker $\left(\alpha_{i}\right)$ effects is again small (27\%), even though it is now positive.

Taking stock. Statistical issues notwithstanding, the type of exercise just sketched reveals the presence and quantitative importance of firm-specific effects in wage determination. One natural interpretation of this finding is to conclude that the Law of One Price does not hold in the labor market, which in turn implies that one should depart from the competitive paradigm as a description of the labor market.

While the set of alternative theoretical constructs to choose from is potentially rather large, we are looking for a model that is both reasonably realistic and tractable enough 
to be empirically implementable. Following Mortensen (2003), we argue that equilibrium search models meet these latter two requirements and offer a natural framework in which to analyze the multiform wage dispersion evident in MEE data.

Equilibrium search models rest upon two basic principles:

1. Labor market competition between employers is the fundamental determinant of wages.

2. Competition is limited by search frictions reflecting information imperfection on the location of job offers.

In the presence of search frictions, wages are determined within a bilateral monopolytype of relationship between employers and workers. While the specific way in which this bilateral monopoly problem is approached varies across particular applications (see the rest of this chapter for a sample), it remains that by varying the intensity of search frictions, the "generic" job search model can be made consistent with a broad array of equilibrium patterns, ranging between the two polar benchmarks of competitive wage equilibrium (when all workers can freely force employers into competition and get paid their marginal productivity) and monopsony wage equilibrium (when employed job search is infinitely costly and firms offer unemployed workers their reservation wages; Diamond, 1971).

Apart from these two limiting cases, equilibrium search models offer simple explanations of why wages vary both across workers and across firms and why some residual wage dispersion remains once heterogeneity has been accounted for. These explanations are reviewed in the next two sections.

\section{A prototypical stationary search model of worker turnover and wage dispersion}

Jolivet, Postel-Vinay and Robin (2005, JPR hereafter) examine empirical features of worker turnover and wage distributions across European countries and the US. ${ }^{5}$ They

\footnotetext{
${ }^{5}$ They use data from the European Community Household Panel (ECHP) and the PSID.
} 
conclude that a successful formal description of worker turnover and dispersion should account for the following broad facts:

1. Workers transit from job to job or in and out of employment.

2. Most job-to-job transitions are associated with a wage increase, yet a sizeable fraction of those transitions (20-40\%) are still associated with a wage cut.

3. Job separation hazards exhibit (slightly) negative duration dependence.

4. Wages are dispersed. Moreover, the distribution of wages in a cross-section of employed workers first-order stochastically dominates the distribution of entry wages and is less positively skewed.

JPR then go on to show that the steady-state predictions of a simple (partial equilibrium) search model does a good job of capturing these features. The model that these authors consider builds on a basic set of formal assumptions that are largely common to all the models we shall review in this chapter. We now list these basic assumptions.

Model description. Time is continuous. The labor market has a unit-mass of infinitely lived workers who can be either employed or unemployed. The labor market is affected by search frictions in that unemployed workers can only sample job offers sequentially at some finite Poisson rate $\lambda_{0}>0$. Employed workers are allowed to search on the job, and face a sampling rate of job offers of $\lambda_{1}>0$. Firm-worker matches are dissolved at rate $\delta>0$. Upon match dissolution, the worker becomes unemployed. ${ }^{6}$

A job offer is a wage draw $w$ from a sampling distribution $F$. The wage $w$ stays constant for the duration of the job spell, i.e. until the match is dissolved for exogenous reasons $(\delta$-shock $)$ or the worker quits into another job upon reception of an outside offer. From the workers' viewpoint, jobs are otherwise identical. Hence, a job offer of $w$ is

\footnotetext{
${ }^{6}$ All "transition parameters", $\lambda_{0}, \lambda_{1}$ and $\delta$ will be considered exogenous throughout this chapter. They can be endogenized within a matching model making a more careful description of labor demand (see Pissarides, 2000, and Mortensen, 2003).
} 
preferred to a job offer of $w^{\prime}$ if $w>w^{\prime} \cdot{ }^{7}$ For simplicity, it is also assumed that any wage draw from $F$ is preferred to unemployment.

In this section, we keep the wage offer distribution $F$ exogenous. For example, wages could be paid a fixed proportion of match productivity, the distribution of which is exogenous. We shall derive it as part of the labor market equilibrium in the next section, as we turn to equilibrium search models.

Steady-state equilibrium. The model is solved in steady state. At a steady-state equilibrium, worker inflows and outflows from any given stock balance each other in order to maintain the stock constant. In particular, this holds true for the proportion of unemployed workers, $u$, and for the cross-sectional distribution of wages across employed workers, $G$.

- Unemployment rate, $u$. Equality of flows in and out of the stock of unemployed workers writes as:

$$
\text { [out }] \quad \lambda_{0} u=\delta(1-u) \quad[\mathrm{in}] \quad \Longleftrightarrow \quad u=\frac{\delta}{\delta+\lambda_{0}} \text {. }
$$

- Cross-sectional wage distribution, G. Equality of flows in and out of the stock of employees paid less than $w,(1-u) G(w)$, writes as:

$$
\begin{gathered}
{[\text { out }] \quad\left[\delta+\lambda_{1} \bar{F}(w)\right](1-u) G(w)=\lambda_{0} u F(w) \quad[\text { in }]} \\
\mathbb{1} \\
G(w)=\frac{F(w)}{1+\kappa \bar{F}(w)} \quad \text { or } \quad F(w)=\frac{(1+\kappa) G(w)}{1+\kappa G(w)}
\end{gathered}
$$

where $\kappa=\frac{\lambda_{1}}{\delta}$ is the average number of job offers that a worker receives between two job destruction shocks (index of search frictions), $\bar{F}=1-F{ }^{8}$

\footnotetext{
${ }^{7}$ Note that this feature of the model is evidently at odds with the observation that many job-to-job transitions are associated with a wage cut. JPR consider a more general model with reallocation shocks and wage cuts upon job-to-job mobility. We shall return to this at several points below.

${ }^{8}$ Throughout this chapter, a bar over a cdf will be used to denote the survivor function.
} 
Estimation and results. Figure 1 is taken out of the JPR paper. Using data from the ECHP and the PSID, they first estimate the density of wage offers, $f$, from the sample of wages of all employed workers who were just hired from unemployment. They estimate the earnings density, $g$, from the sample of all employees' wages. An alternative estimator of $f$ can then be constructed from $g$ by differentiating the second equation in (3). ${ }^{9}$ We can first verify that the wage offer densities are to the left of earnings densities. Moreover, the distribution of wage offers is systematically less dispersed than the distribution of wages among all employees and is more positively skewed. Finally, the discrepancy between $f$ and $g$ is reasonably well captured by formula (3). We view this last result as strongly supportive of the general structure of job search models: it implies that employed workers accept take up jobs associated with better wages than unemployed workers, and, what's more, that this selection process is somehow related to the process of job mobilityi.e. the capacity of workers to contact more than one employer at a time-as equation (3) indicates that the extent to which $G$ dominates $F$ is fully characterized by only one parameter, $\kappa$, which is estimated from job mobility data, independently of any information on wages.

While the above results show the model's broad consistency with observations 1 and 4 in the list given at the beginning of this section, JPR also examine the model's rendering of duration dependence in job spell hazards. Because wages are fixed over any given job spell, the hazard rate of a job spell associated with some wage $w$ is constant over time and equal to $\lambda_{1} \bar{F}(w)$. The model thus predicts negative duration dependence in a cross-section of job spells through wage heterogeneity: job spells with longer elapsed durations tend to be associated with higher wages, which in turn makes them more likely to last longer in the future. While this prediction is qualitatively consistent with observation 3 , it comes at a high price: in the JPR model (and indeed, as we shall see shortly, in wage posting models in general), negative duration dependence hinges on the constancy of wages over any given job spell, which implies that workers only move up the "wage ladder". This rules out not only job-to-job transitions associated with wage cuts (thus contradicting

\footnotetext{
${ }^{9}$ The parameter $\kappa$ can be estimated separately from job duration data.
} 

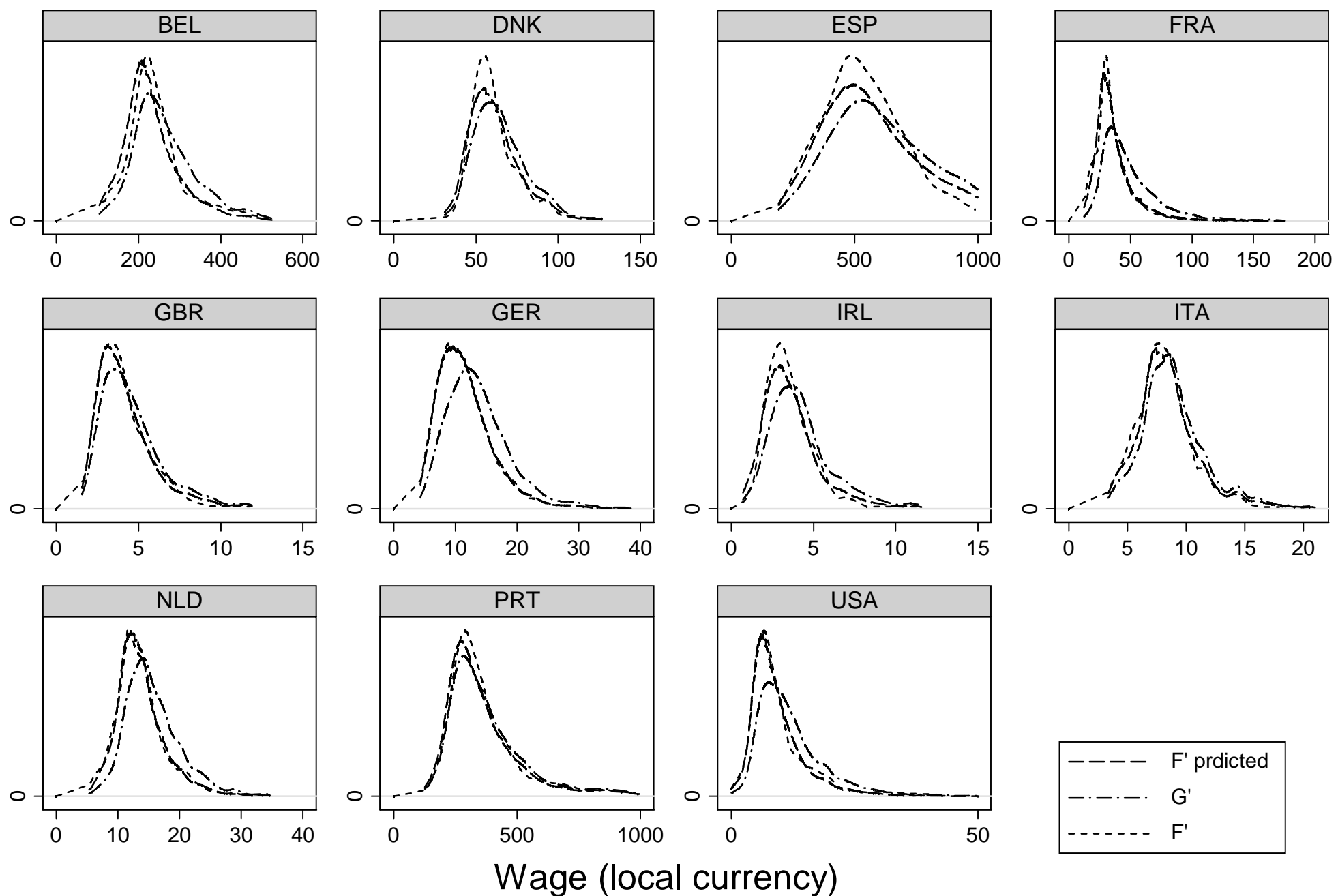

Wage (local currency)

Figure 1: Wage Densities 
observation 2), but also any within-job wage dynamics. These qualitative shortcomings will be addressed in sections 4 and 5 below. Moreover, the model's quantitative success at predicting negative duration dependence in job spell hazards is more mitigated. JPR indeed show that the source of duration dependence built into the model turns out to be quantitatively weak, if still significant, and conclude that, in most of the countries from their ECHP sample, cross-spell differences in the arrival rates of job offers must be appealed to in order to replicate the observed duration profiles of job spell hazard rates. Such differences arise endogenously in wage posting model when worker search intensity is made endogenous (Christensen et al., 2005). ${ }^{10}$

More on the steady-state assumption. Figure 2 depicts the French and U.S. series of unemployment rates as they can be computed from a cross-section of employed and unemployed workers and as they can be computed from worker flows in and out of employment and unemployment across two consecutive years. Our data sources are the French labor Force Survey and the U.S. Current Population Survey. Both series are remarkably close.

Perhaps the most intriguing implications of both Figures 1 and 2 is that the steadystate assumptions seems to be a reasonable one. Said more precisely, it seems that observed time series variations mostly reflect variations in predicted steady states.

In the case of the unemployment rate (Figure 2), this should not sound too surprising considering the yearly frequency of the data from which the Figure 2 is constructed and the average duration of an unemployment spell. More precisely, the law of motion of unemployment in the model writes down as:

$$
\frac{d u_{t}}{d t}=\delta\left(1-u_{t}\right)-\lambda_{0} u_{t}
$$

implying a half-life for $u_{t}$ of $\ln 2 /\left(\delta+\lambda_{0}\right)$. Given the very small estimated values for $\delta$, this is well approximated by $\ln 2 / \lambda_{0}$, i.e. 0.7 times average unemployment duration.

\footnotetext{
${ }^{10}$ All this refers to "artificial" duration dependence due to heterogeneity. To our knowledge, "true" duration dependence (i.e. non-stationarity of individual hazards) has so far not been modeled in a job search context. (Yet see below footnote 16.)
} 


\section{Unemployment Rates From Stocks and Flows}

(French LFS and US CPS)

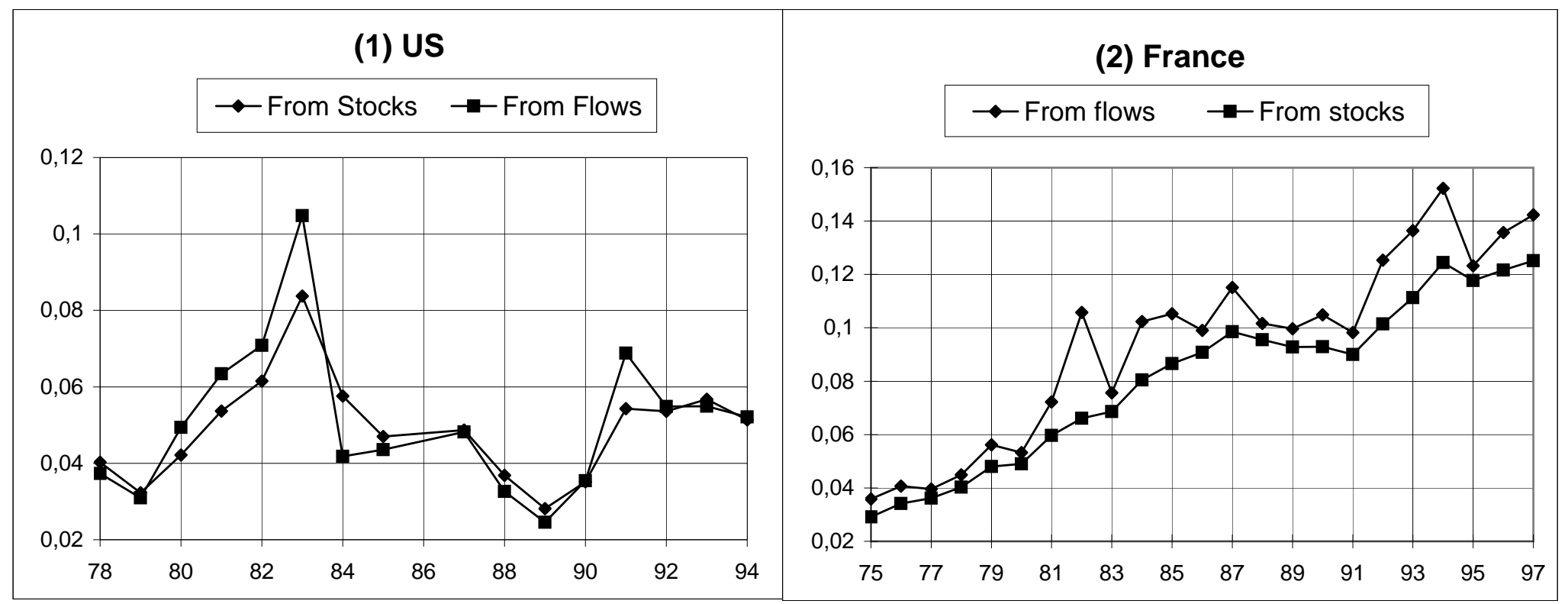

From stocks: Fraction of unemployed in March of year $\mathrm{t}$

From flows: $t / t+1$ job destruction rate divided by $t / t+1$ job destruction rate plus $t / t+1$ re-employment rate

Rates are computed by comparing the state in March of year $t+1$ to the state in March of year $t$. 
This number would typically be less than 6 months in continental Europe, and around a couple of months in the US. In other words, dynamic adjustments of the unemployment rate are "quick" when the reference period is one year, which explains why the steady-state assumption is a reasonable approximation. ${ }^{11}$

Turning to the offered and earned wage distributions, $F$ and $G$, it is well known that earnings distributions change slowly over time, certainly more slowly than unemployment rates. $^{12}$ If this is also the case for the wage offer distribution, then it must also be true for the friction index, which consequently approximately satisfies the equation:

$$
\kappa=\frac{F_{t}(w)-G_{t}(w)}{G_{t}(w) \overline{F_{t}}(w)}
$$

for all $w$.

\section{Steady-state market equilibrium with search fric- tions}

In the preceding section, we argued that a simple stationary Markovian model of worker turnover based on a reservation wage policy fits the data reasonably well. The model was partial equilibrium in that it kept the distribution of wage offers, $F$, exogenous. We now want to describe two extensions of the prototypical search models endogenizing the wage offer distribution: Burdett and Mortensen's (1998) wage posting model, and Postel-Vinay and Robin's (2002) sequential auction model.

\subsection{Wage Posting Models - Burdett and Mortensen (1998)}

Burdett and Mortensen's (1998, BM hereafter) wage posting model builds on the following assumptions about wage formation:

- Firms make take-it-or-leave-it offers to workers. They decide ex ante what wage to offer, then commit to paying the chosen wage for the duration of the job. In particular, they do not counter outside offers.

\footnotetext{
${ }^{11}$ Interestingly, Figure 2 gives the impression of a slightly better fit in the US than in France. This is consistent with average unemployment duration being about a third in the US of what it is in France.

${ }^{12}$ It is the usual practice to describe changes in inequality across decades.
} 
- Equilibrium wages are a Nash equilibrium of the non cooperative game where firms choose what wage to post and workers decide what wages to accept.

In the basic BM model, workers and firms are homogeneous and the production technology is linear in labor.

In this context, Burdett and Mortensen show a very important result. Even though firms and workers are ex-ante identical, the equilibrium wage offer distribution $F$ is a continuous, nondegenerate distribution. This is because firms play a mixed strategy in the wage posting game's equilibrium. The idea of the proof is very simple. Suppose that a mass of firms were offering the same wage $w$. Then, each of these firms would gain from offering slightly more because the additional flow of workers that it could attract from the other firms via on-the-job search would more than compensate the marginal loss in profit per worker.

Although the BM model generates equilibrium wage dispersion among identical firms and workers (and thus potentially explains the residual wage variance left unexplained by the AKM decomposition), the predicted wage density in the homogeneous model is upward sloping, which is at odds with empirical evidence (see Figure 1). Fortunately, it is easy to change that by allowing for heterogeneity in match productivity.

BM model with heterogeneous productivity. The BM model can be extended by assuming that firms differ in their (constant) marginal productivity of labor, $p$. In the sequel we shall refer to $p$ as firm type. Upon receiving a job offer, workers draw the type of the firm from which the offer comes from an (exogenous) sampling distribution, $\Gamma(p)$. Let $F(w)$ denote the corresponding equilibrium sampling distribution of wage offers. For it to be a Nash equilibrium, it must be the case that:

1. Each firm of type $p \in \operatorname{Supp}(\Gamma)=[\underline{p}, \bar{p}]$ offers a wage $w(p)$ that maximizes the steady-state profit flow $\pi(w, p)=(p-w) \ell(w)$, where $\ell(w)$ is steady-state employment:

$$
\ell(w)=\frac{(1-u) g(w)}{f(w)}=\frac{(1-u)(1+\kappa)}{[1+\kappa \bar{F}(w)]^{2}}
$$


and $1-u=\frac{\lambda_{0}}{\lambda_{0}+\delta}$.

2. The sampling distributions of wages and firm types are equal, i.e. $F[w(p)]=\Gamma(p)$.

The equilibrium solution is such that the firm with the smallest productivity, $\underline{p}$, offers unemployed workers their reservation wage $\phi$ and hires workers only from the unemployment pool. Moreover, free entry will ensure that $\underline{p}=\phi$. All other firms with productivity $p$ in $[\underline{p}, \bar{p}]$ offer: ${ }^{13}$

$$
w(p)=p-\left[1+\kappa_{1} \bar{\Gamma}(p)\right]^{2} \int_{\phi}^{p} \frac{d x}{\left[1+\kappa_{1} \bar{\Gamma}(x)\right]^{2}}
$$

Empirical applications of the BM model. An appealing property of this version of the BM model is that any observed wage offer distribution $F$ can be rationalized in equilibrium as resulting from a properly chosen underlying productivity distribution $\Gamma$, provided that the resulting wage equation (5) defines an increasing function $w(p)$ (an implementability condition that is not prohibitively restrictive in practice). Partly as a consequence of this flexibility, the BM model has received a lot of attention from microeconometricians. Bowlus, Kiefer and Neuman (1995 and forth.) assume a discrete distribution of productivity. This turns out to be very cumbersome if there are too many support points. Van den Berg and Ridder (1998) assume segmented homogeneous markets. Workers differ in productivity across labor markets but not within. Bontemps, Robin and Van den Berg (2000) propose a simple estimation procedure for the heterogeneous productivity version of the BM model. Bontemps, Robin and Van den Berg (1999) have both heterogeneous productivity and heterogeneous leisure costs, but impose equal job offer arrival rates for employed and unemployed workers. Christensen, Lentz,

\footnotetext{
${ }^{13}$ This result is a direct consequence of the Envelope Theorem applied to the profit maximisation problem:

$$
\frac{d \pi(p, w(p))}{d p}=\frac{\partial \pi(p, w(p))}{\partial p}=\ell(w(p))=\frac{(1-u)(1+\kappa)}{[1+\kappa \bar{F}(w(p))]^{2}}=\frac{(1-u)(1+\kappa)}{[1+\kappa \bar{\Gamma}(p)]^{2}}
$$
}

As free entry further implies that $\pi(\underline{p}, \phi)=0$, integration of the above equation leads to:

$$
(p-w(p)) \ell(p)=\pi(p, w(p))=\int_{\phi}^{p} \frac{(1-u)(1+\kappa)}{\left[1+\kappa_{1} \bar{\Gamma}(x)\right]^{2}} d x .
$$

Hence $w(p)$. 
Mortensen, Neumann and Werwatz (2005) estimate an extension of the BM model featuring endogenous search intensity (declines with wage). The estimation technique draws on Bontemps, Robin, and Van den Berg (2000). Barlevy (2005) proposes an estimation technique based on record statistics.

The estimation technique developed by Bontemps, Robin and Van den Berg (2000) is very simple and can be applied to other empirical microeconomic equilibrium models. It proceeds in the following steps:

1. Estimate $G$ and $g$ nonparametrically.

2. Estimate $\kappa$ by maximization of the likelihood of worker job and wage mobility, ${ }^{14}$ replacing $F$ by

$$
\widehat{F}(w ; \kappa)=\frac{(1+\kappa) \widehat{G}(w)}{1+\kappa \widehat{G}(w)} .
$$

3. Estimate the inverse wage function (5),

$$
p(w)=w+\frac{1+\kappa \bar{F}(w)}{2 \kappa f(w)}=w+\frac{1+\kappa G(w)}{2 \kappa g(w)},
$$

to retrieve the underlying productivity distribution $\Gamma{ }^{15}$

Successes and failures of the BM model. The main lesson drawn from empirical implementations of the BM model is that, while it fits worker turnover and wage distributions well, the underlying distribution $\Gamma$ of firm productivity required to achieve that good fit is implausible: it exhibits an exceedingly long right tail. It is easy to understand why. High-productivity firms have a lot of market power in the BM model. This tends to concentrate wages toward the lower part of the distribution. In order to generate the very long, thin tails of observed wage distributions, productivity distributions with much longer and thinner tails are thus necessary.

Finally, as we already emphasized in section 3, a substantial shortcoming of the wage posting model lies in its predicted pattern of individual wage dynamics: the wage posting

\footnotetext{
${ }^{14}$ The hazard rate of a job spell associated with wage $w$ is $\delta+\lambda_{1} \bar{F}(w)=\delta(1+\kappa \bar{F}(w))$.

${ }^{15}$ The aforementioned implementability condition of the BM equilibrium clearly appears here. For the (inverse) wage function to be increasing, it has to be the case that the observed cross-sectional earnings density $g$ does not increase "too steeply" over any part of its support.
} 
assumption rules out any within-job wage dynamics by assumption, and further implies that workers can only experience wage gains as they move directly from job to job. Both of these features are counter-factual, which calls for further theoretical thinking about the wage formation process. A very promising line of research has been opened by Stevens (2004) and Burdett and Coles (2003), who analyze posting models where firms post wagetenure contracts instead of single wages.

\subsection{Sequential Auctions: Postel-Vinay and Robin (2002)}

One of the reasons why the BM model fails to fit the data is because there is too little between-firm competition. Postel-Vinay and Robin (2002, PR hereafter) propose to temper the monopsonistic inclination of employers by allowing employers to counter the outside offers made to their employees. As we shall see, this alternative hypothesis about wage formation also helps in addressing the issue of wage dynamics.

The model allows for two-sided heterogeneity in match productivity: firms are heterogeneous as in the BM model and workers now differ in a ability parameter $\varepsilon$. The marginal productivity of a match between a type $\varepsilon$ worker and a type $p$ firm is $p \varepsilon$ (i.e., workers are perfect substitutes, up to their type $\varepsilon$ ). As they receive offers, workers draw firms types $p$ from the same sampling distribution $F$, whatever their type or labor market status.

Wage contracts. Wage contracts are negotiated between employers and employees under complete information: When an unemployed worker contacts an employer, the latter observes the employment status of the worker and his/her ability. When an employed worker contacts an outside firm through on-the-job search, the latter observes the worker's current wage and ability as well as the incumbent employer's type. The worker also informs his/her current employer about the exact type of the poaching firm. Wage contracts can be renegotiated by mutual consent only. Lastly, PR assume that employers make takeit-or-leave-it offers to workers, an assumption that is relaxed in Cahuc, Postel-Vinay and Robin (2006). 
Let $V_{0}(\varepsilon)$ denote the lifetime value of unemployment for a worker of type $\varepsilon$. Let $V(w ; \varepsilon, p)$ denote the lifetime value of current wage $w$ for a worker $\varepsilon$ in firm $p$. When an unemployed worker meets a potential employer, the latter offers a wage $\phi_{0}(\varepsilon, p)$ that is just enough to make the former prefer employment to unemployment. That is, $\phi_{0}(\varepsilon, p)$ solves the equation:

$$
V\left(\phi_{0}(\varepsilon, p) ; \varepsilon, p\right)=V_{0}(\varepsilon)
$$

When an employed worker paid $w$ in firm $p$ receives an offer from a firm $p^{\prime}$, the two employers compete to hire the same worker. They play a Bertand game, the solution of which is such that the more productive firm bids the worker away from the less productive one and pays the value-equivalent of the best wage the latter firm can offer, which equals match productivity: in other words, the worker extracts the full surplus from the less productive employer. For instance, if $p<p^{\prime}$, then firm $p^{\prime}$ eventually hires the worker for a mobility wage $\phi\left(\varepsilon, p, p^{\prime}\right)$ that solves the equation:

$$
V\left(\phi ; \varepsilon, p^{\prime}\right)=V(\varepsilon p ; \varepsilon, p)
$$

More precisely, depending on the values of $p, p^{\prime}$ and the worker's initial wage $w$, the consequence of the worker receiving an outside offer is one of the following three events:

- If $p<p^{\prime}$, the worker moves to $p^{\prime}$ for a wage $\phi\left(\varepsilon, p, p^{\prime}\right.$ ) (possibly lower than $w$-see below).

- If $p>p^{\prime}$ and $w<\phi\left(\varepsilon, p^{\prime}, p\right)$, the worker stays at firm $p$ but her/his wage is raised to $\phi\left(\varepsilon, p^{\prime}, p\right)$.

- If $\phi\left(\varepsilon, p^{\prime}, p\right)<w$ nothing happens.

PR further show that equations (6) and (7) can be solved in closed form. Specifically, all wages have the following expression (for a pair $p \leq p^{\prime}$ ):

$$
\begin{aligned}
\phi\left(\varepsilon, p, p^{\prime}\right) & =\varepsilon \cdot \phi\left(1, p, p^{\prime}\right) \\
& =\varepsilon \cdot\left(p-\frac{\lambda_{1}}{\rho+\delta} \int_{p}^{p^{\prime}} \bar{F}(x) d x\right),
\end{aligned}
$$


where $\rho$ is the discount rate and where "starting" wages $\phi_{0}(\varepsilon, p)=\phi(\varepsilon, b, p)$ (i.e. being unemployed is like working at a firm of productivity $b \leq \underline{p}$ ).

This wage equation highlights two important theoretical predictions of the PR model. First, wages gradually increase over a given job spell as the worker receives outside offers which her/his employer matches. The PR model thus has non-trivial, if monotonic, within-job wage dynamics. Second, some voluntary job-to-job changes will be associated with a wage cut. Consider a type $\varepsilon$ worker employed at a type $p$ firm, who at some point in time is lucky enough to draw an outside offer from a poacher of the exact same type $p$ as her/his current employer. Bertrand competition will then leave the worker with the full rent associated with an $(\varepsilon, p)$ match: according to (8), the resulting wage will equal $\varepsilon p$, the worker's marginal productivity. Now suppose that this same worker later receives an offer from a more productive firm $p^{\prime}>p$. According to the mechanism outlined above, the worker will quit his job at firm $p$ to take up the job offered by firm $p^{\prime}$, with a mobility wage given by (8) which is strictly less than her/his initial wage, $\varepsilon p$. This results from a straightforward option value effect: being paid her/his marginal productivity at firm $p$, the worker has no hope of seeing her/his wage further raised if $\mathrm{s} /$ he stays at firm $p$. The worker is therefore willing to give up some income today in exchange for the prospect of future wage raises (offered by firm $p^{\prime}$ only) as $\mathrm{s} /$ he moves from firm $p$ to firm $p^{\prime}$. Drawing a parallel with the BM model, in which workers only moved toward jobs associated with higher w's, in the PR model workers only move up the productivity ladder-i.e. they only move toward jobs offered by higher type $p$ firms - even though such moves can be associated with a cut in $w .^{16}$

Overall, the PR model thus predicts qualitatively richer individual wage dynamics than the wage posting models previously reviewed. How far it goes into quantitatively explaining the observed dynamic behavior of wages will be examined in section 5 .

\footnotetext{
${ }^{16}$ This particular implication of the PR model is potentially counter-factual, just as BM's implication of workers only moving up the wage ladder is counter-factual. Yet as $p$ is not directly observed in the data (at the very least, it is arguably less readily measurable than individual wages) this particular implication of the PR model is difficult to assess empirically.
} 
Equilibrium distribution. Any employed worker is thus paid a wage $w=\phi(\varepsilon, q, p)$, where $(\varepsilon, p)$ are the match characteristics and $q$ is the productivity of the employer from which the worker was last able to extract the full surplus in a wage negotiation (this equals $b$ if the last mobility was out of unemployment). Thanks to the perfect substitutability of workers, employers are indifferent to worker ability. As a consequence, the steadystate equilibrium distribution of worker ability $\varepsilon$ is the same in all firms, irrespective of their types $p$ (there is no sorting). Further exploiting the balance of inflows and outflows between employment states, between firms and within firms, PR arrive at the following characterization of the equilibrium distribution of the triple $(\varepsilon, p, q)$ :

1. $\varepsilon$ has some exogenous distribution, say $H$.

2. $(q, p)$ are independent of $\varepsilon$ (no sorting).

3. The distribution of $p$ is the steady-state distribution of firm labor productivity across employees, with cdf:

$$
G(p)=\frac{F(p)}{1+\kappa \bar{F}(p)},
$$

where $\kappa=\lambda_{1} / \delta$ and where $F$ is the sampling distribution of firm types that job seekers face.

4. The distribution of $q$ given $p$ has cdf:

$$
q \mid p \sim\left(\frac{\delta+\mu+\lambda_{1} \bar{F}(p)}{\delta+\mu+\lambda_{1} \bar{F}(q)}\right)^{2}
$$

on $\{b\} \cup[\underline{p}, p]$.

Estimation. PR use the French wage register data (DADS) unmatched with firm accounting data. The only information on a firm is thus its ID number. Yet, this is enough for identification. Using the steady-state distribution of $(\varepsilon, q, p)$ derived in the previous paragraph, one can write down the mean wage paid by a firm of type $p$ to its employees 


$$
\begin{aligned}
y(p) & \equiv \mathbb{E}(w \mid p) \\
& =\mathbb{E}(\varepsilon) \cdot\left(p-[1+\kappa \bar{F}(p)]^{2} \int_{p_{\min }}^{p} \frac{1+\left(1-\frac{\rho}{\rho+\delta}\right) \kappa \bar{F}(q)}{[1+\kappa \bar{F}(q)]^{2}} d q\right) .
\end{aligned}
$$

Assume that $y$ is an increasing function of $p$. A job-to-job mobility then only occurs if the mean wage is higher in the poaching than in the incumbent firm. Consequently, Bontemps, Robin and Van den Berg's technique for estimating the BM model can be applied to estimate $\lambda_{1}$ and $\delta$ and the distribution of firm-level mean wages $(y)$ among employees, i.e. $G[p(y)]$ where $p(y)$ is the inverse of $y(p)$. In a second step, inverting equation (10), where (9) is used to substitute $F[p(y)]$, identifies $p(y)$ (and thus $F(p)$ ).

Application. PR apply the model to obtain a log-wage variance decomposition similar to the one produced by AKM:

$$
\operatorname{Var}(\ln w)=\operatorname{Var}(\ln \phi(\varepsilon, q, p))= \begin{cases}\operatorname{Var}(\ln \varepsilon) & \text { (person effect) } \\ +\operatorname{Var} \mathbb{E}[\ln \phi(1, q, p) \mid p] & \text { (firm effect) } \\ +\mathbb{E} \operatorname{Var}[\ln \phi(1, q, p) \mid p] & \text { (effect of frictions) }\end{cases}
$$

The interpretation of the first two terms in the above decomposition as the contributions of, respectively, person and firm effects is rather straightforward. These first two terms directly parallel the contributions of $\alpha_{i}$ and $\psi_{j}$ to total log wage variance in the AKM model (1).

As to the third term, it is the share of within-firm wage variance which is not due to worker heterogeneity in ability $\varepsilon$. This term is the counterpart of the share of wage variance that was left unexplained in the AKM decomposition, i.e. the variance due to the residual term in (1). Within PR's structural model, though, this residual withinfirm variance has a clear interpretation: it reflects conditional heterogeneity in terms of individual histories of outside offers: identical workers employed at identical firms can still earn different wages depending on how lucky they both were in drawing outside job offers. ${ }^{17}$ This ex-post heterogeneity arises because of the randomness of the process of

\footnotetext{
${ }^{17}$ Formally, recalling that wages are a combination of a triple of random variables $(\varepsilon, q, p)$, this residual variance reflects conditional heterogeneity of $q$ given $(\varepsilon, p)$.
} 
outside offers, i.e. because of search frictions, hence the label "effect of frictions" that was attached to it in (11).

PR's quantitative results confirm the importance of search frictions in wage determination: the third component in (11) accounts for about 50\% of total log wage variance, with little variation across worker categories. The person effect explains $40 \%$ of $\operatorname{Var}(\ln w)$ for managers and quickly drops to 0 for unskilled categories. These last numbers are in the same ballpark as AKM's result of about 20\%, all categories pooled.

\subsection{Sequential Auctions and Bargaining: Cahuc, Postel-Vinay and Robin (2006)}

Cahuc, Postel-Vinay and Robin (2006, CPR hereafter) extend the PR model to further investigate the wage-productivity relationship. The CPR contribution is two-fold. First, contrary to PR (and AKM), CPR merge the administrative data on wages with firm accounting data in order to obtain direct estimates of the firms' productivity levels. The literature before CPR (including PR) was inferring those productivity levels from observed wages and from the structure of the particular model that was estimated. In other words, it was predicting what the wage-productivity relationship or what the productivity distribution should be, given the model's structure, in order to implement the observed distribution of wages as an equilibrium. Using actual data on productivity removes one degree of freedom and offers a way of testing the theory.

Second, CPR relax the assumption of firms making take-it-or-leave-it offers to workers and give bargaining power to the latter. The PR sequential auction model has it that wages are less than marginal labor productivity, so that nontrivial rent-sharing takes place between workers and employers. Yet, it cannot tell whether sheer competition between employers in the presence of search friction is enough to quantitatively explain the workers' share of value-added observed in linked wage-productivity data. To answer this question, it is necessary to nest the PR model in a more general model allowing for an additional, "non-competitive" source of rent sharing. Bargaining is a natural candidate. In the CPR model, unemployed workers negotiate with a single employer in a conventional 
way, but when an employed worker receives an outside job offer, a three-player bargaining process is started between the worker, her/his incumbent employer and the poacher. This bargaining process is modeled using a version of the Rubinstein (1982) infinite-horizon, alternating-offers bargaining game.

labor productivity. In order to construct a labor productivity value for each firm $j$ of the sample, CPR estimate the following production function:

$$
Q_{j t}=\theta_{j}\left(\alpha_{1} L_{1 j t}+\alpha_{2} L_{2 j t}+\ldots\right)^{\xi}, \quad \sum_{j} \theta_{j}=0,
$$

where $Q_{j t}$ is firm $j$ 's value added at date $t$ (sales minus intermediate costs; available from the firm accounting data), and $L_{1 j t}, L_{2 j t}$, etc. are firm $j$ 's employment of various occupation categories (secretaries, engineers, etc.) defining different labor markets. Parameters $\alpha_{1}, \alpha_{2}, \ldots$ are the corresponding occupation-wide average ability.

It should be raised at this point that inferring measures of firm productivity from firmlevel data on value-added as CPR do requires assumptions about the competitive environment on the product market. For instance, one can assume that all firms produce the same multi-purpose good and that the good market is competitive. In this case, a proper production function is estimated. If, however, firms operate on an imperfectly competitive product market, then a reduced-form firm-revenue equation is estimated. In any case, for the equilibrium sequential auction model to apply, we need this firm-revenue/production function to exhibit constant returns to scale, a property that is confirmed by the firm data that we use to estimate the model. Nevertheless, diminishing (apparent) returns to labor, labor demand, and interactions between labor market structure and goods market structure are definitely important areas to investigate.

In market $k$, firm $j$ thus has labor productivity $p_{j k}=\alpha_{k} \theta_{j}$. CPR estimate $p_{j k}$ for each firm $j$ and each market $k$.

Wage contracts. The fact that workers now have some positive bargaining power entails the following changes from the PR wage contracts. Consider two firms with productivity levels $p$ and $p^{\prime}$ competing for worker $\varepsilon$. The maximum values that these firms can 
yield to the worker are, respectively, $V(\varepsilon p ; \varepsilon, p)$ and $V\left(\varepsilon p^{\prime} ; \varepsilon, p^{\prime}\right)$. Suppose that $p^{\prime}>p$. Then the outcome of the strategic bargaining game exposed in CPR is such that the type $p^{\prime}$ firm wins the worker and pays a wage $\phi\left(\varepsilon, p, p^{\prime}\right)$ such that

$$
V\left(\phi ; \varepsilon, p^{\prime}\right)=(1-\beta) V(\varepsilon p ; \varepsilon, p)+\beta V\left(\varepsilon p^{\prime} ; \varepsilon, p^{\prime}\right)
$$

where $\beta \in[0,1]$ measures the worker's bargaining power. This outcome is clearly reminiscent of the "generalized Nash solution" to a bargaining problem between a firm of type $p^{\prime}$ and a worker of type $\varepsilon$ where the worker's threat point would be to take up employment at the less productive, type $p$ firm for a wage of $\varepsilon p$. Equation (12) has the following closed-form solution:

$$
\phi\left(\varepsilon, p, p^{\prime}\right)=\varepsilon \cdot\left(p^{\prime}-(1-\beta) \int_{p}^{p^{\prime}} \frac{\rho+\delta+\lambda_{1} \bar{F}(x)}{\rho+\delta+\lambda_{1} \beta \bar{F}(x)} d x\right),
$$

where the notation is the same as for the PR model. Note that, as expected, the CPR bargaining model confounds itself with the PR sequential auctions model in the case where workers have zero bargaining power, $\beta=0$.

Application. CPR estimate workers' bargaining power $\beta$ to equal zero for all low skill categories and to lie between 0 and 0.3 for high skill workers (depending on the industry). CPR's main finding is thus that between-firm competition alone is essentially enough to explain - or at the very least plays a prominent role in explaining - wage determination in France over the period 1993-2000. Yet although skilled workers are found by CPR to have less bargaining power than is usually estimated, they are still able to capture a substantial share of the job surplus for reasons that cannot be entirely explained by between-employer competition for labor services. This is an interesting result which calls for further research in order to better understand what hides inside the "black box" of the bargaining power parameter $\beta$. The game-theoretic model featured in CPR's paper interprets this parameter in terms of different response times for workers and firms and different time discount rates. But empirical evidence on the dependence of these variables on such intuitive candidate determinants as education or trade union density, for example, is still missing. 

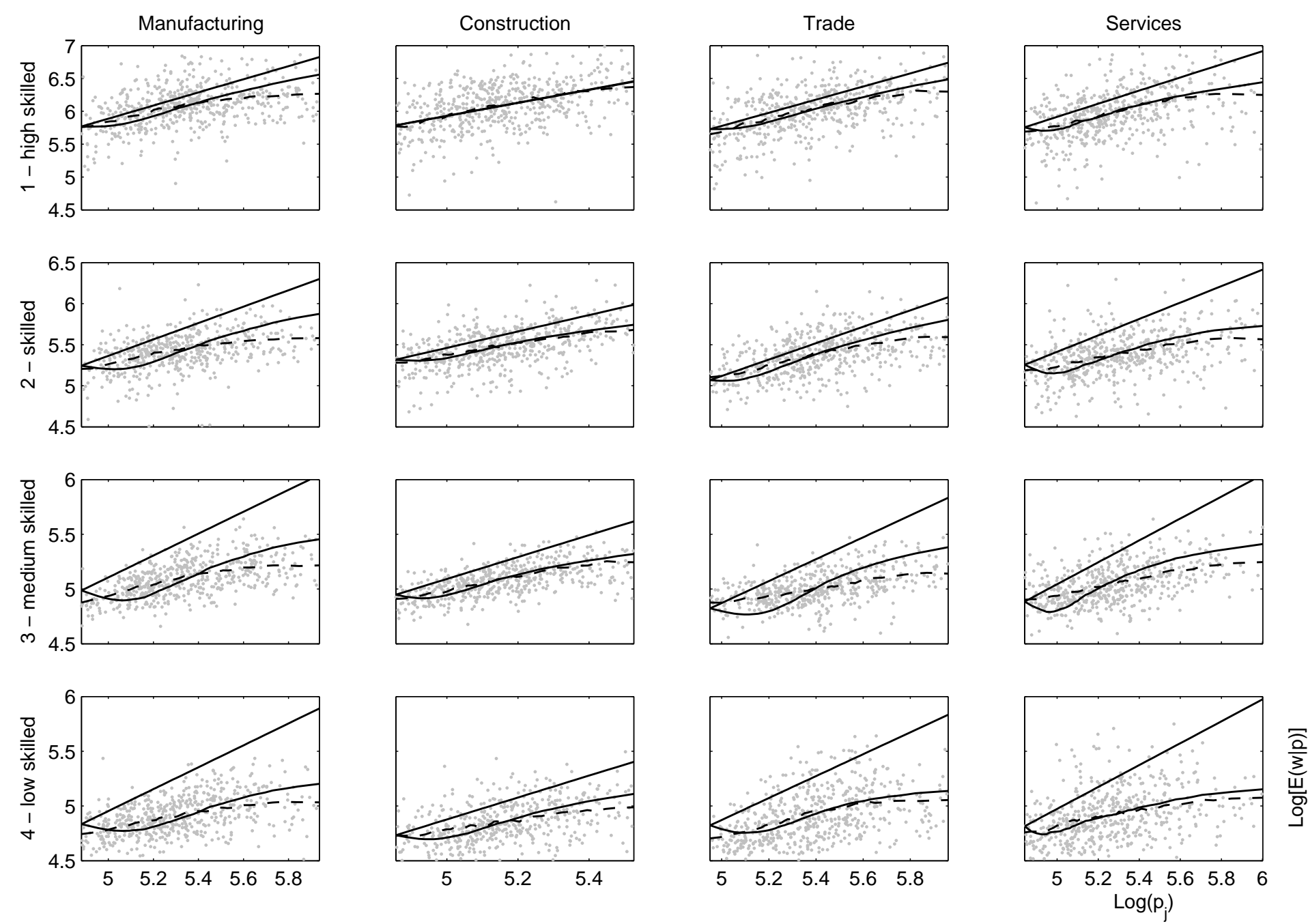

Figure 3: The Wage-Productivity Relationship 
A glance at the various panels of Figure 3 next shows that the model is reasonably consistent with the observed wage-productivity relationship, thus improving on what seemed to be a failure of the BM wage posting model. More specifically, the Figure suggests two remarkable stylized facts. One is that the wage paid by the lowest- $p$ firms in all four samples and all categories of workers displayed is always very close to match productivity (solid line) at $\underline{p}$. The other is that profit rates are increasing with productivity: the gap between wages and productivity - which again is near zero at $\underline{p}$ - becomes substantial at higher values of $p$. CPR's structural model correctly captures this phenomenon which, incidentally, remained concealed in AKM's reduced-form analysis.

\section{$5 \quad$ Wage Dynamics}

The discussion was thus far focused on "cross-sectional" aspects of the data, namely wage dispersion or the wage-productivity relationship. Yet job search models are inherently dynamic and do have strong predictions about the process followed by individual wages over time. Even though this is not (yet) directly related to matched employer-employee data, it is interesting to ask whether those predictions are sensible, or more generally if we can learn anything from structural job search models about individual wage dynamics. This is the question that we ask in this final section. We begin by putting twenty years of empirical literature on wage dynamics in a nutshell, and then turn back to job search models.

\subsection{Empirical models of income dynamics}

The literature studying individual labor earnings dynamics, as they are observed from worker panel data, is literally huge. ${ }^{18}$ While the "true" earnings process is still to be discovered, a twofold conclusion seems to emerge from that literature. First, earnings shocks are highly persistent over time. Second, it takes a fairly rich mix of random

\footnotetext{
${ }^{18}$ A somewhat arbitrary selection includes the seminal papers by Lillard and Willis (1978), Lillard and Weiss (1979), MaCurdy (1982) and Abowd and Card (1989), the comprehensive comparative analysis of recent developments by Alvarez, Browning and Ejrnæs (2001), Blundell and Preston (1998) for an application to U.K. data, and Meghir and Pistaferri (2004) as an example of a state-of-the-art paper in this field.
} 
processes to replicate the intricate autocovariance structure of earnings.

Indeed there is a long tradition of fitting ARMA-type models to individual income trajectories in worker panel data. The archetypal such ARMA-type decomposition of the individual earnings process features a martingale or a highly persistent Markov component, on top of a fixed-effect and a transitory (MA) shock. In its simplest form, it looks like:

$$
\begin{cases}w_{i t}=\alpha_{i}+s_{i t}^{P}+s_{i t}^{T}, & \text { with } \alpha_{i} \text { a fixed effect, } \\ s_{i t}^{P}=s_{i, t-1}^{P}+u_{i t}, & \text { with } u_{i t} \text { i.i.d. } \\ s_{i t}^{T}=\sum_{\ell=0}^{q} \theta_{\ell} \varepsilon_{i, t-\ell}, & \text { with } \varepsilon_{i t} \text { i.i.d. and typically } q=0 \text { or } 1 .\end{cases}
$$

While the dynamic properties of individual earnings - notably persistence - are by now well diagnosed by this kind of decomposition, the economic mechanisms at the root of these properties are still unknown or at least controversial. Progress in this area is once more likely to come from a structural approach. We now turn to job search models as potential structural candidates.

\subsection{What do job search models have to say on income dynamics?}

Probably owing to the analytical difficulty of combining a realistic job search model with individual level shocks, research on individual wage dynamics within structural search models is just taking off and the contributions reviewed in this section are still somewhat preliminary. Yet they do contain some promising results.

Wage dynamics in PR's sequential auctions model. Postel-Vinay and Robin (2002) briefly assess their model's quantitative rendition of individual wage dynamics by comparing the observed and predicted distributions of yearly wage changes among various subgroups of workers. They do so separately for job movers (i.e. workers who have experienced a job-to-job transition within the year) and job stayers (i.e. workers who haven't). Their results are summarized in tables 3 and 4.

Table 3 reveals that the predicted distribution of wage changes among job movers firstorder stochastically dominates the observed one. It does so to a larger extent in its bottom than in its top half, meaning that, while the PR model does have a theoretical mechanism predicting that workers may be willing to take wage cuts as they change employers, this 
Table 3: Distribution of yearly wage changes in the PR model: Job movers

\begin{tabular}{llccccccc}
\hline \hline \multirow{2}{*}{ Occupation } & & Median & \multicolumn{5}{c}{ \% obs such that $\Delta \ln w \leq$} \\
& & $\Delta \ln w$ & -0.10 & -0.05 & 0 & 0.05 & 0.10 \\
\hline Executives, engineers & Data & $3.1 \%$ & 23.6 & 28.5 & 38.1 & 55.1 & 65.4 \\
& Simul. & $3.1 \%$ & 13.0 & 22.9 & 38.8 & 55.1 & 65.4 \\
Admin. and sales supervisors & & & & & & & \\
& Data & $3.7 \%$ & 21.6 & 27.1 & 36.6 & 54.3 & 65.2 \\
& Simul. & $3.3 \%$ & 2.7 & 12.4 & 35.0 & 55.8 & 66.7 \\
Technical supervisors & & & & & & & \\
& Data & $3.8 \%$ & 14.0 & 20.2 & 32.2 & 55.5 & 67.3 \\
Administrative support & Simul. & $2.8 \%$ & 4.2 & 10.0 & 32.2 & 57.8 & 71.8 \\
& & & & & & & \\
Skilled manual workers & Data & $2.2 \%$ & 21.5 & 28.7 & 40.7 & 60.5 & 69.2 \\
& Simul. & $5.1 \%$ & 1.1 & 6.1 & 24.3 & 49.7 & 64.4 \\
& & & & & & & \\
Sales and service workers & Data & $0.5 \%$ & 33.2 & 37.7 & 49.2 & 62.3 & 72.0 \\
& Simul. & $4.5 \%$ & 1.7 & 7.5 & 28.2 & 51.7 & 66.0 \\
& & & & & & & \\
\multirow{2}{*}{ Unskilled manual workers } & Data & $1.4 \%$ & 31.3 & 37.7 & 45.1 & 58.0 & 67.5 \\
& Simul. & $3.0 \%$ & 0.2 & 5.5 & 31.0 & 59.1 & 75.3 \\
& & Data & $-1.3 \%$ & 33.5 & 42.9 & 54.5 & 63.4 & 72.3 \\
& Simul. & $3.6 \%$ & 0.2 & 4.4 & 29.4 & 55.5 & 70.0 \\
\hline \hline
\end{tabular}


Table 4: Distribution of yearly wage changes in the PR model: Job stayers

\begin{tabular}{|c|c|c|c|c|c|c|c|}
\hline \multirow[b]{2}{*}{ Occupation } & & \multirow{2}{*}{$\begin{array}{c}\text { Median } \\
\Delta \ln w\end{array}$} & \multicolumn{5}{|c|}{$\%$ obs such that $\Delta \ln w \leq$} \\
\hline & & & -0.10 & -0.05 & 0 & 0.05 & 0.10 \\
\hline \multirow[t]{2}{*}{ Executives, engineers } & Data & $2.7 \%$ & 6.6 & 11.3 & 28.5 & 64.4 & 80.0 \\
\hline & Simul. & $0 \%$ & 0 & 0 & 85.8 & 93.9 & 96.6 \\
\hline \multirow[t]{2}{*}{ Admin. and sales supervisors } & Data & $2.6 \%$ & 7.9 & 12.9 & 28.6 & 65.2 & 81.1 \\
\hline & Simul. & $0 \%$ & 0 & 0 & 84.7 & 94.8 & 97.3 \\
\hline \multirow[t]{2}{*}{ Technical supervisors } & Data & $2.5 \%$ & 6.6 & 11.9 & 29.6 & 68.1 & 85.0 \\
\hline & Simul. & $0 \%$ & 0 & 0 & 87.2 & 95.8 & 97.9 \\
\hline \multirow[t]{2}{*}{ Administrative support } & Data & $2.2 \%$ & 7.9 & 12.4 & 30.0 & 69.8 & 84.2 \\
\hline & Simul. & $0 \%$ & 0 & 0 & 84.9 & 94.7 & 97.3 \\
\hline \multirow[t]{2}{*}{ Skilled manual workers } & Data & $1.9 \%$ & 7.9 & 15.0 & 34.9 & 69.5 & 85.1 \\
\hline & Simul. & $0 \%$ & 0 & 0 & 85.6 & 94.5 & 97.2 \\
\hline \multirow[t]{2}{*}{ Sales and service workers } & Data & $2.5 \%$ & 7.4 & 12.8 & 31.4 & 64.5 & 79.1 \\
\hline & Simul. & $0 \%$ & 0 & 0 & 84.0 & 94.9 & 97.5 \\
\hline \multirow[t]{2}{*}{ Unskilled manual workers } & Data & $2.2 \%$ & 7.7 & 14.6 & 32.9 & 66.4 & 81.9 \\
\hline & Simul. & $0 \%$ & 0 & 0 & 84.5 & 94.2 & 96.8 \\
\hline
\end{tabular}


mechanism is not quantitatively strong enough.

Turning to table 4 (which relates to job stayers), one sees that the predicted distribution is clearly much more concentrated around zero wage change than the observed one. The only force governing within-job wage dynamics in the PR model is the sampling of outside job offers by workers: as employers match these offers, workers obtain wage raises. There is thus nothing to cause wage cuts within a job spell in the model, and (as the table shows), simulated wages are indeed downward rigid within jobs. What's more, this mechanism of offer matching does not seem to be quantitatively strong enough to account for observed wage increases within jobs.

Overall, failure of the PR model to replicate individual wage dynamics comes mainly from its tendency to predict excessive downward wage rigidity, and indeed total downward wage rigidity within job spells. Now, when comparing PR's predictions to actual data, it should be mentioned that PR's simulations presented in tables 3 and 4 are run assuming the absence of measurement error. Yet adding classical (i.e. symmetric) measurement error to the simulation model is unlikely to help much, as the predicted distribution is more skewed than the observed one. Moreover, recent attempts at measuring the actual extent of downward wage flexibility ${ }^{19}$ suggest that, even though much of the observed downward wage flexibility is due to measurement error (Gottschalk, 2005; Dessy, 2005), such downward flexibility is still a real phenomenon, even among job stayers. Something thus has to be added to PR's model in order to explain these "genuine" within-job wage cuts.

A clear shortcoming of the PR model is the lack of individual-level productivity - or "match quality" — shocks. The assumption that individual or firm productivity is fixed over time is certainly an unrealistic one, and, to the extent that wages are related to productivity, wage changes are likely to reflect (at least partially) changes in productivity. Moreover, adverse individual productivity shocks line up as a possible cause for withinjob wage cuts, hence potentially correcting the PR's model counter-factual prediction of

\footnotetext{
${ }^{19}$ See e.g. Smith (2000) and Nickell and Quintini (2003) on U.K. data, Gottschalk (2005) on U.S. data and Dessy (2005) for a multi-country study based on data from the ECHP.
} 
downward wage rigidity within a job spell.

Introducing individual-level shocks. Postel-Vinay and Turon (2005, PT hereafter) investigate the capacity of the PR model with simple i.i.d. match-level productivity shocks to capture the main aspects of observed earnings processes. They thus show how the combined assumptions of on-the-job search and wage renegotiation by mutual consent can act as a realistic "internal propagation mechanism" of i.i.d. shocks. This combination of assumptions, which they take up from the PR model, indeed implies that purely transitory productivity shocks are translated into persistent wage shocks with a covariance structure that they find to be consistent with the data.

Neglecting measurement error to simplify the argument (measurement error is found to explain much, but not all, of the observed downward wage flexibility), the PT model delivers the following dynamic structure for log wages (the model is now in discrete time): $w_{i t}=\alpha_{i}+v_{i t}$, where $\alpha_{i}$ is a fixed effect and $v_{i t}$ is a shock such that

$$
v_{i, t+1} \mid v_{i t}= \begin{cases}v_{i t} & \text { with probability } \bar{F}\left(v_{i t}\right)-\frac{\lambda_{1}}{1-\delta} \bar{F}\left(v_{i t}\right)^{2}, \\ v^{\prime}<v_{i t} & \text { with density } f\left(v^{\prime}\right), \\ v^{\prime}>v_{i t} & \text { with density } 2 \frac{\lambda_{1}}{1-\delta} f\left(v^{\prime}\right) \bar{F}\left(v^{\prime}\right),\end{cases}
$$

where $F$ is the sampling distribution of underlying productivity shocks. Conditional on individual fixed-effects $p$, PT thus predict that wages follow a first-order, nonlinear Markovian process based on a specific acceptance/rejection scheme of i.i.d. wage innovations.

This particular structure turns out to capture the covariance structure of wages amazingly well. PT estimate the structural model using twelve years of data on high-educated workers of both genders from the BHPS, then simulate a panel of income data. ${ }^{20}$ Among other illustrations of their model's goodness of fit, they fit the canonical ARMA process (13) to both real and simulated data. The results are in table 5. Also, for a more direct comparison with the PR model without shocks, we can use the PT simulations to con-

\footnotetext{
${ }^{20}$ For lack of space, we do not discuss PT's estimation procedure. Yet it differ quite fundamentally from the methods presented in the previous two sections that were used to estimate the BM or the PR model: while these latter exploit almost exclusively the data's cross-section dimension, PT's estimation technique is based on dynamic moments - as is standard estimation of an ARMA model like (13).
} 
Table 5: Job Search vs. ARMA Decomposition

\begin{tabular}{|c|c|c|c|c|c|}
\hline & \multicolumn{5}{|c|}{$\operatorname{Cov}\left(\Delta w_{i t}, \Delta w_{i, t+s}\right), s=\ldots$} \\
\hline & 0 & 1 & 2 & 3 & 4 \\
\hline BHPS & $\begin{array}{l}0.032 \\
(0.001)\end{array}$ & $\begin{array}{l}-0.009 \\
(0.001)\end{array}$ & $\begin{array}{l}-0.000 \\
(0.001)\end{array}$ & $\begin{array}{l}-0.001 \\
(0.001)\end{array}$ & $\begin{array}{l}0.000 \\
(0.001)\end{array}$ \\
\hline \multirow[t]{3}{*}{ Simulated } & $\begin{array}{l}0.035 \\
(0.001)\end{array}$ & $\begin{array}{c}-0.009 \\
(0.001)\end{array}$ & $\begin{array}{c}-0.002 \\
(0.001)\end{array}$ & $\begin{array}{l}0.002 \\
(0.001)\end{array}$ & $\begin{array}{l}0.001 \\
(0.001) \\
\end{array}$ \\
\hline & \multicolumn{3}{|c|}{ ARMA parameters: } & \multirow{2}{*}{\multicolumn{2}{|c|}{$\begin{array}{c}\text { Test of OI rest. } \\
\text { Test Statistic } \\
\text { (df: } p \text {-value) }\end{array}$}} \\
\hline & $\operatorname{Var}\left(u_{i t}\right)$ & $\operatorname{Var}\left(\varepsilon_{i t}\right)$ & $\theta_{1}$ & & \\
\hline BHPS & $\begin{array}{l}0.010 \\
(0.001)\end{array}$ & $\begin{array}{l}0.011 \\
(0.001)\end{array}$ & $\begin{array}{l}0.119 \\
(0.045)\end{array}$ & \multicolumn{2}{|c|}{$\begin{array}{c}65.52 \\
(52: 0.099)\end{array}$} \\
\hline Simulated & $\begin{array}{l}0.011 \\
(0.001)\end{array}$ & $\begin{array}{l}0.012 \\
(0.001)\end{array}$ & $\begin{array}{l}0.110 \\
(0.039)\end{array}$ & \multicolumn{2}{|c|}{$\begin{array}{c}63.76 \\
(52: 0.127)\end{array}$} \\
\hline
\end{tabular}

Table 6: Distribution of yearly wage changes in the PT model

\begin{tabular}{llcccccc}
\hline \hline & & Median & \multicolumn{4}{c}{ \% obs such that $\Delta \ln w \leq$} \\
& & $\Delta \ln w$ & -0.10 & -0.05 & 0 & 0.05 & 0.10 \\
\hline \multirow{2}{*}{ All workers } & BHPS & $0 \%$ & 22 & 34 & 50 & 60 & 73 \\
& Simulated & $-1.5 \%$ & 28 & 40 & 51 & 60 & 73 \\
\hline \hline
\end{tabular}

struct a table similar to tables 3 and 4 reporting the observed and predicted distributions of yearly wage changes (table 6).

In both tables, the similarity between the results obtained with the simulated and the true BHPS samples is striking (in spite of a slight tendency of the model to over-predict large wage cuts). A particularly intriguing result in table 5 is that, as commonly found in the literature, a significantly positive variance for the innovation of the permanent earnings shock $u_{i t}$ is estimated, both for the actual and simulated data. One would, however, wrongly conclude to the presence of a random walk component of the individual earnings process, as we know that, for the simulated data, the fitted ARMA process is misspecified and the true DGP is stationary. This illustrates the difficulty of numerically distinguishing between a linear process truly exhibiting a unit root and other types of a highly persistent (possibly nonlinear) processes. This point was thoroughly investigated in a related context by Baker (1997), who compares a linear ARMA decomposition of 
earnings dynamics similar to (13) to a competing "profile-heterogeneity" model featuring individual heterogeneity in (linear) earnings-experience profiles using twenty years of PSID data. Even though he finds evidence of a unit root when fitting the ARMA process to his sample, tests based on specifications nesting the two models lead to rejection of the unit root hypothesis. Overall, Baker (1997) concludes that the evidence favors the "profileheterogeneity" specification over the unit root model.

The PT model in turn suggests that wage persistence could/should be thought of as the outcome of a specific acceptance/rejection scheme of i.i.d. shocks. Incidentally, a look around existing theories of individual income dynamics reveals that the PT model is not the only one propounding this type of scheme. The process in (14) is indeed formally reminiscent of predictions obtained by Harris and Holmström (1982), Thomas and Worral (1988), or Beaudry and DiNardo (1991) in models of self-enforcing wage contracts designed to allocate risk between a risk-neutral employer and a risk-averse employee faced with uncertainty about match productivity and/or market opportunities.

The PT results thus suggest that job search models potentially offer structural explanations of the widely documented persistence of earnings shocks and can potentially help with the interpretation of observed wage dynamics. In particular, as the rates of transition between labor market states $\left(\delta\right.$ and $\left.\lambda_{1}\right)$ are key determinants of the individual earnings process in (14), the PT results highlight the link between labor market competition (as measured by the probability of raising outside job offers when employed), worker mobility across jobs, and individual earnings dynamics.

What about human capital accumulation? One serious shortcoming of all the theories reviewed thus far is that they completely overlook human capital accumulation as a potential driving force of the wage process. Ongoing work by Bagger, Fontaine, Postel-Vinay and Robin (BFPR hereafter) incorporates human capital accumulation in a version of the PR model. Assuming piece-rate wages, BFPR derive the following structural 
log-wage equation:

$$
w_{i t}=\alpha_{i}+k_{i t}+p_{j(i, t)}-\int_{q_{i t}}^{p_{j(i, t)}}\left[1-\frac{\rho \lambda_{1} \bar{F}(x)}{1-\rho(1-\delta)}\right] d x
$$

where $p_{j(i, t)}$ and $q_{i t}$ are firm productivity levels that evolve along with the occurrence of outside job offers following similar rules as in PR, and where $k_{i t}$ is worker $i$ 's human capital and follows an arbitrary Markov process. The BFPR wage equation thus not only features human capital with flexible dynamics (two important additions to the PR/PT efforts), but also clearly identified firm effects (which were absent from the PT model). This allows to go back to matched employer-employee data (as BFPR propose to do, using Danish register data) with a structural model which is potentially capable of explaining the relationship between wages and productivity, from both a cross-section and a dynamic perspective.

To conclude this section, it seems that the sequential auction model delivers a promising description of wage dynamics both within and between employment spells. Yet, much remains to be done in the way of explaining features of income dynamics such as income persistence, the role of human capital accumulation, experience vs. tenure effects, and the role of firm heterogeneity. This now opens the door to a new research agenda, aiming at bridging the gap between the "wage dispersion" (AKM...) and "income dynamics" (Abowd and Card...) literatures.

\section{Where do we go from there?}

In this chapter we have given a review - although a partial one - of existing empirical structural models of wage dispersion and wage dynamics, with a particular emphasis on some new empirical properties of wage dispersion and individual wage and employment processes revealed by the most recent descriptions based on matched employer-employee data. We have focused on equilibrium job search models with on-the-job search. The theoretical models feature heterogeneous productivity attributes for both firms and workers, and wage setting mechanisms that include alternative assumptions of wage posting, sequential auctions and wage bargaining. 
This class of models are used to provide new results about the decomposition of logwage variance into firm effects, worker effects and the effect of labor market frictions. The model can also be used to estimate workers' bargaining power in a general equilibrium model of the labor market with interfirm competition limited by search frictions. It also provides a simple enough framework that allows to replicate the complex empirical properties of actual dynamic wage processes.

We now list a few desirable extensions.

One richness of this literature is also a drawback. It offers a choice between two alternative wage setting mechanisms: wage posting and sequential auctions. They correspond to different sets of assumptions about the information that is available - or exploitableto a worker and a firm about each other's characteristics when a matching opportunity occurs. More work is needed to understand which set of assumptions is better suited to describe a particular labor market. It is likely that skill, occupation and industry are crucial determinants.

The particular equilibrium search models considered in this review assume away any potential source of sorting. Indeed these models predict the absence of sorting as a straightforward consequence of the combined assumption of perfect substitutability between workers within a firm and constant returns to scale. Nevertheless, it is hard to believe that there is no sorting on unobservables (to the econometricians but observables to the interacting agents) in the labor market. Moreover, the no-sorting prediction is at odds with results from the literature on hedonic wage/competitive equilibrium models. More research is thus called for to obtain estimates of the degree of sorting in matched employer/employee data that are robust to the existence of endogenous mobility. In particular, nesting the two theoretical paradigms of job search and hedonic wages is one of the most exciting theoretical and empirical projects for future research in labor economics.

A final desirable avenue for future research relates to macroeconomics and policy analysis. It is possible to use these models to analyze equilibrium effects of policy interventions only if contact rates and job destruction rates are endogenized. Here again, Dale Mortensen opened the way in his 2000 paper, "Equilibrium Unemployment with Wage 
Posting: Burdett-Mortensen meet Pissarides". Mortensen shows that it is rather easy to incorporate features of equilibrium matching models into the equilibrium search models and thus turn these latter into fully general equilibrium models. While much more work is needed to identify and estimate matching functions using micro data, reasonable calibrations of the additional parameters should still be of great help in the analysis of such large-scale policy measures as the EITC or WFTC for instance.

Still in the field of macroeconomics, and apart from policy, a strong limitation of the models considered in this chapter is that they are only tractable in steady-state equilibrium. It is considerably more difficult to describe out-of-equilibrium dynamics here than in Pissarides's canonical matching model. This is because some of the endogenous variables are distributions, i.e. infinite dimensional parameters, and it is very hard to analyze their dynamics (see Shimer, 2003). Issues about possible analytical solutions, numeric simulations or acceptable approximations, are all very uncertain at the present.

\section{References}

[1] Abowd, J. M. and D. Card (1989), "On the Covariance Structure of Earnings and Hours Changes", Econometrica, 57(2), 411-45.

[2] Abowd, J. M., R. Creecy, F. Kramarz (2002), "Computing Person and Firm Effects Using Linked Longitudinal Employer-Employee Data", Cornell University Working Paper (http://www.crest.fr/pageperso/dr/kramarz/note on computation revised.pdf).

[3] Abowd, J. M., Kramarz, F., Lengermann, P., and Roux, S. (2003), "Interindustry and firm-size wage differentials in the United States and France", Cornell University working paper.

[4] Abowd, J. M., F. Kramarz and D. N. Margolis (1999) "High Wage Workers and High Wage Firms", Econometrica, 67, 251-333. 
[5] Alvarez, J., M. Browning, and M. Ejrnæs (2001), "Modelling Income Processes with Lots of Heterogeneity", CAM discussion paper 2002-01.

[6] Baker, M. (1997), "Growth-Rate Heterogeneity and the Covariance Structure of LifeCycle Earnings", Journal of Labor Economics, 15 (2), 338-75.

[7] Barlevy, G. (2005), "Estimating Models of On-the-Job Search using Record Statistics" Federal Reserve Bank of Chicago Working Paper (http://www.chicagofed.org/publications/workingpapers/papers/wp2003-18.pdf).

[8] Beaudry, P. and J. DiNardo (1991), "The Effect of Implicit Contracts on the Movement of Wages over the Business Cycle: Evidence from Micro Data", Journal of Political Economy, 99(4), 665-88.

[9] Berry, S., J. Levinsohn and A. Pakes (1995), "Automobile Prices in Market Equilibrium", Econometrica, vol.63, no.4, 841-90.

[10] Bontemps, C., J.-M. Robin, and G.-J. Van den Berg (1999), "An Empirical Equilibrium Search Model with Continuously distributed Heterogeneity of workers' Opportunity Costs of Employment and Firms' productivities, and Search on the Job", International Economic Review, 40 (4), 1039-74.

[11] Bontemps, C., J.-M. Robin and G. J. Van den Berg (2000), "Equilibrium Search with Continuous Productivity Dispersion: Theory and Non-Parametric Estimation", International Economic Review, 41 (2), 305-58.

[12] Bowlus, A. J., N. M. Kiefer, and G. R. Neumann (1995), "Estimation of equilibrium wage distributions with heterogeneity," Journal of Applied Econometrics, Vol. 10, S119-31.

[13] Bowlus, A.J., N.M. Kiefer, and G.R. Neumann (2001), "Equilibrium Search Models and the Transition from School to Work," International Economic Review, 42 (2): 317-343. 
[14] Burdett, K. and M. G. Coles, (2003) , "Equilibrium Wage-Tenure Contracts", Econometrica, 71, 5, pp. 1377-1404.

[15] Burdett, K. and D. T. Mortensen (1998), "Wage Differentials, Employer Size and Unemployment", International Economic Review, 39, 257-73.

[16] Blundell, R. and I. Preston (1998), "Consumption Inequality and Income Uncertainty", Quarterly Journal of Economics, 113, 603-40.

[17] Cahuc, P., F. Postel-Vinay and J.-M. Robin (2006), "Wage Bargaining with On-thejob Search: Theory and Evidence". Forthcoming Econometrica.

[18] Christensen, B. J., R. Lentz, D. T. Mortensen, G. R. Neumann and A. Werwatz (2005), "On the Job Search and the Wage Distribution", Journal of Labor Economics, January 2005, vol. 23(1), pp. 31-58.

[19] Danilov, D. and J. R. Magnus (2005), "Least squares in sparse systems", work in progress (http://center.uvt.nl/staff/magnus/).

[20] Dessy, O. (2005) "Nominal Wage Rigidity in Europe: Estimates and Institutional Causes", Università di Milano mimeo.

[21] Diamond, P. A. (1971), "A model of price adjustment", Journal of Economic Theory, Vol. 3, pp. 156-68.

[22] Eckstein, Z. and K. I. Wolpin (1990), "Estimating a Market Equilibrium Search Model from Panel Data on Individuals", Econometrica, Vol.58, 783-808.

[23] Eckstein, Z. and K. I. Wolpin (1995), "Duration to First Job and the Return to Schooling: Estimates from a Search-Matching Model", Review of Economic Studies, 1995, 62, 263-86.

[24] Gottschalk, P. (2005), "Downward Nominal Wage Flexibility: Real or Measurement Error?", Review of Economics and Statistics, 87 (3), 556-68. 
[25] Harris, M. and B. Holmström (1982), "A Theory of Wage Dynamics", Review of Economic Studies, 49, 315-33.

[26] Heckman, J. J. and B. Honoré (1990), "The Empirical Content of the Roy Model", Econometrica, Vol. 58, No. 5, 1121-49.

[27] Jolivet, G., F. Postel-Vinay and J.-M. Robin (2005), "The Empirical Content of the Job Search Model: Labor Mobility and Wage Distributions in Europe and the US", in Bunzel, H., B. J. Christensen, G. R. Neumann and J.-M. Robin, editors, Structural Models of Wage and Employment Dynamics, Elsevier Science.

[28] Lillard, L. A. and Y. Weiss (1979), "Components of Variation in Panel Earnings Data: American Scientists 1960-1970", Econometrica, 47(2), 437-54.

[29] Lillard, L. A. and R. J. Willis (1978), "Dynamic Aspects of Earnings Mobility", Econometrica, 46(5), 437-54.

[30] MacLeod, W. B. and J. M. Malcomson (1993), "Investments, Holdup, and the Form of Market Contracts", American Economic Review, 83(4), 811-37.

[31] MaCurdy, T. E. (1982), "The Use of Time-Series Processes to Model the Error Structure of Earnings in a Longitudinal Data Analysis", Journal of Econometrics, 18(1), 83-114.

[32] Meghir, C. and L. Pistaferri (2004), "Income Variance Dynamics and Heterogeneity", Econometrica, Vol. 72, 1-32.

[33] Mortensen, D. (2000), "Equilibrium Unemployment with Wage Posting," in H. Bunzel, B.J. Christiansen, P. Jensen, N.M. Kiefer and D.T. Mortensen, eds., Panel Data and Structural Labor Market Models, Amsterdam: Elsevier, 2000.

[34] Mortensen, D. (2003), Wage Dispersion: Why Are Similar Workers Paid Differently?, MIT Press. 
[35] Nickell, S. J., and G. Quintini (2003), "Nominal Wage Rigidity and the Rate of Inflation", Economic Journal, 133 (October), 762-81.

[36] Pissarides, C. A. (2000), Equilibrium Unemployment Theory, 2nd edition. Cambridge, MA: MIT Press.

[37] Postel-Vinay, F. and J.-M. Robin (2002), "Equilibrium Wage Dispersion with Worker and Employer Heterogeneity", Econometrica, 70 (6), 2295-350.

[38] Postel-Vinay, F. and H. Turon (2005), "On-the-job Search, Productivity Shocks, and the Individual Earnings Process", manuscript, University of Bristol and PSE (http://www.ecn.bris.ac.uk/www/ecfybpv/wp/Shocks.pdf).

[39] Rubinstein, A. (1982), "Perfect Equilibrium in a Bargaining Model", Econometrica 50, 97-109.

[40] Shimer, R. (2003), "Dynamics in a Model of On-the-Job Search," (paper presented at the SED meeting, Paris, June 2003).

[41] Smith, J. C. (2000), "Nominal Wage Rigidity in the United Kingdom", Economic Journal, 110, C176-95.

[42] Stevens, M., (2004), "Wage-Tenure Contracts in a Frictional labor Market: Firms' Strategies for Recruitment and Retention", The Review of Economics Studies, 71(2), 247, pp: 535-551.

[43] Thomas, J. and T. Worrall (1988), "Self-Enforcing Wage Contracts", Review of Economic Studies, 55, 541-54. 